\title{
Main Directions of Recent Works on Al-Zn-Based Alloys for Foundry Engineering
}

\author{
P.K. Krajewski, A.L. Greer, and W.K. Krajewski
}

\author{
(Submitted October 13, 2018; in revised form March 2, 2019; published online April 26, 2019)
}

\begin{abstract}
The composition and structural modification of high-aluminum zinc alloys and high-zinc aluminum alloys influence their wear properties and structural stability. The work described has been aimed at improving properties of the sand-cast Al-Zn-based foundry alloys, particularly their ductility and dimensional stability, by melt inoculation and/or change of chemical composition. In a series of studies, high-aluminum $\mathrm{Zn}$ (25-26) wt.\% Al-(1-2.5) wt.\% $\mathrm{Cu}$ and high-zinc Al-(27-30) wt.\% Zn-(1.5-2.5) wt.\% Cu alloys have been doped with different levels of added Ti and Mn. The alloys' structure and mechanical properties have been studied using scanning electron microscopy (SEM), light microscopy (LM), dilatometry and pin-on-disk wear measurements. A small addition of $\mathrm{Ti}$ introduced with $\mathrm{Zn}-4 \mathrm{Ti}$ master alloy leads to significant grain refinement of the high-aluminum zinc alloys. A small addition of Ti introduced with Al-3Ti-0.15C master alloy leads to significant grain refinement of the high-zinc aluminum alloys. In the ternary alloys, partially replacing $\mathrm{Cu}$ with $\mathrm{Ti}$ and/or $\mathrm{Mn}$ allows dimensional changes to be reduced while preserving good wear properties.
\end{abstract}

Keywords grain refinement, high-aluminum zinc alloys, highzinc aluminum alloys, mechanical properties, structural and dimensional stability

\section{Introduction}

Cast alloys with Al- and Zn-based matrices show an increasing range of uses, and the world production of such castings is still increasing-Fig. 1 (Ref 1).

Among the cast alloys based on the Al-Zn system, there are high-aluminum zinc (h-Al Zn) alloys containing 15-40 wt.\% Al and high-zinc aluminum (h- $\mathrm{Zn} \mathrm{Al}$ ) alloys containing 20$40 \mathrm{wt} . \% \mathrm{Zn}$. These alloy types have a wide range of potential applications because of their good strength of 200-400 $\mathrm{MPa}$ and simultaneously good tribological and damping properties. Both alloy types usually contain $2-5$ wt. $\% \mathrm{Cu}$ which increases the strength and improves the tribological properties.

The main trends of investigations on the mentioned alloys result from their several disadvantageous characteristics. These include a relatively low value of allowable operating temperature; great sensitivity to overheating of the liquid metal leading to oxidation of alloy components and resulting in decrease in

This article is an invited submission to JMEP selected from presentations at the 73rd World Foundry Congress and has been expanded from the original presentation. 73WFC was held in Krakow, Poland, September 23-27, 2018, and was organized by the World Foundry Organization and Polish Foundrymen's Association.

P.K. Krajewski and W.K. Krajewski, Faculty of Foundry Engineering, AGH University of Science and Technology, 30 Mickiewicza Av., 30-059 Kraków, Poland; and A.L. Greer, Department of Materials Science and Metallurgy, University of Cambridge, 27 Charles Babbage Road, Cambridge CB3 0FS, UK. Contact e-mail: krajwit@agh.edu.pl. strength; instability of structure and dimensions caused by phase transformations in the solid alloys over long periods after casting; and susceptibility to coarse grain structure developing after sand-mold casting, resulting in difficult feeding of interdendritic regions and decreased ductility (Ref 2).

Relatively low creep strength limits application of the $\mathrm{Zn}-\mathrm{Al}$ alloys with increased addition of $\mathrm{Al}$ to about $150{ }^{\circ} \mathrm{C}$. At this temperature, the tensile strength of the zinc alloys decreases to 100-140 MPa. One of the possibilities for improving these properties in the temperature range up to $150{ }^{\circ} \mathrm{C}$ is development of composites with fibrous reinforcement, for example, by adding up to about 20 vol.\% of $\mathrm{SiC}$ (Ref 3), $\mathrm{TiO}_{2}$ (Ref 4), $\mathrm{Al}_{2} \mathrm{O}_{3}$ (Ref 5), glass-fiber (Ref 6) or others, to the alloy Zn27 wt.\% Al-3 wt.\% $\mathrm{Cu}$ (ZA27).

Reference 3 presents the mechanical properties of pressure die-cast ZA27 alloy reinforced with 10 and 20 vol.\% of 50- and $300-\mu \mathrm{m} \mathrm{SiC} \mathrm{particles.} \mathrm{It} \mathrm{was} \mathrm{stated} \mathrm{that} \mathrm{at} \mathrm{room} \mathrm{temperature} \mathrm{the}$ reinforcement increases hardness from about $110 \mathrm{HB}$ to about $150 \mathrm{HB}$, decreases UTS from about 370 to about $220 \mathrm{MPa}$ and significantly increases wear resistance measured by weight loss and wear rate. It was also noted that the $\mathrm{SiC}$ reinforcement does not influence the UTS at an elevated temperature of $150{ }^{\circ} \mathrm{C}$.

$\mathrm{TiO}_{2}$ particles of diameter 30-50 $\mu \mathrm{m}$ were added in amount of 2-6 wt.\% to ZA27 alloy cast into a permanent mold (Ref 4). Addition of 6 wt. $\% \mathrm{TiO}_{2}$ increased UTS from about $300 \mathrm{MPa}$ to about $380 \mathrm{MPa}$ and hardness from about 125 to about 137 $\mathrm{HB}$ and decreased elongation from about 9.5 to about 5.5\% (the initial values refer to the matrix alloy without $\mathrm{TiO}_{2}$ addition). With the addition of 10 vol. $\% \mathrm{Al}_{2} \mathrm{O}_{3}$, the room-temperature tensile strength of ZA27 alloy increases by $10 \%$, and with the addition of 20 vol. $\% \mathrm{Al}_{2} \mathrm{O}_{3}$ it increases by $15 \%$. The tensile strength of ZA27 alloy in the range $100-200{ }^{\circ} \mathrm{C}$ increases from about $100 \mathrm{MPa}$ (for the alloy without filler) to $250-350 \mathrm{MPa}$ at $200{ }^{\circ} \mathrm{C}$ after addition of $20 \mathrm{vol} . \%$ of $\mathrm{Al}_{2} \mathrm{O}_{3}$, while the wear drops practically to zero (Ref 5).

High-pressure die-cast ZA-27/glass-fiber composites, reinforced with 1, 3 and $5 \mathrm{wt} . \%$ of E-glass of 4-5 $\mu \mathrm{m}$ diameter and 4-6 mm length, showed significant increases in UTS, compres- 

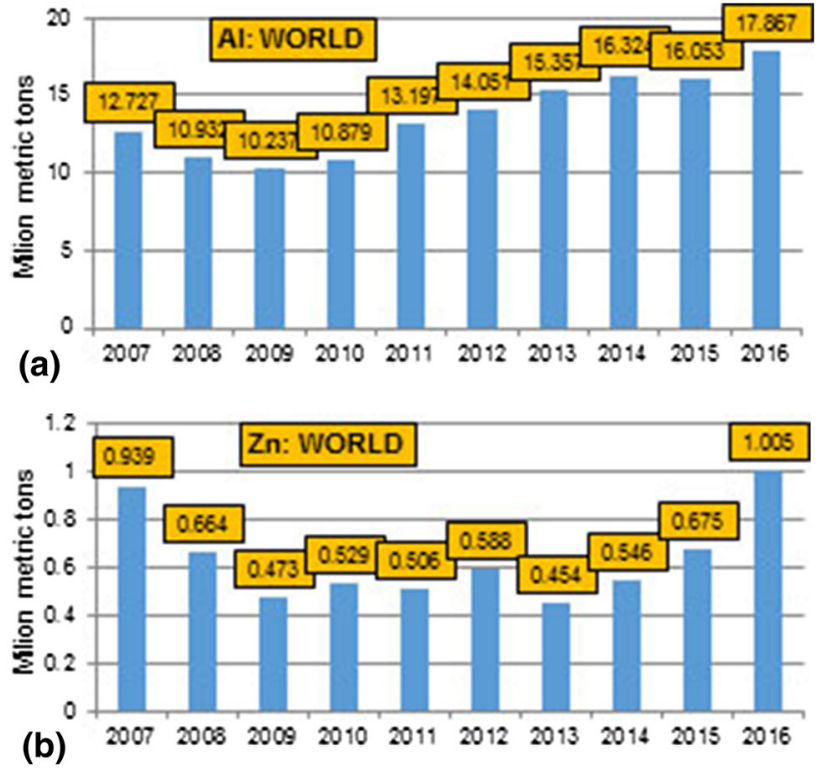

Fig. 1 World production of $\mathrm{Al}$ and $\mathrm{Zn}$ castings over the years 2007-2016 (based on data in Ref 1)

sive strength and hardness, but also decreases in ductility and impact strength (Ref 6).

It is well known that the addition of copper to Al-Zn-based alloys prolongs the development of phase changes and the related dimensional changes (Ref 7) which can cause problems in some applications of such alloys (Ref 8). Furthermore, the addition of $\mathrm{Cu}$ leads to the formation of the metastable $\varepsilon-\mathrm{CuZn}_{4}$ phase which takes part in the so-called four-phase reaction to form the stable $\mathrm{T}^{\prime}-\mathrm{Al}_{5} \mathrm{Cu}_{4} \mathrm{Zn}$ phase. The $\varepsilon-\mathrm{CuZn}_{4}$ phase is present in the structure of high-aluminum zinc for a long time after casting (Ref 7), while the four-phase reaction can lead to an increase in volume of the $\mathrm{Zn}-\mathrm{Al}-\mathrm{Cu}$ alloys, by as much as 4.5\% (Ref 9). This disadvantageous effect can be decreased by substituting copper with silicon, totally (Ref 8 ) or partially (Ref 10), by partial substitution of copper with silicon and nickel (Ref 11), or by heat treatment and partial substitution of copper with Ti (Ref 12-15). Such modification of the ZA27 alloy composition results not only in increased dimensional stability but also in increased wear resistance.

As mentioned above, the Al-Zn-based alloys show a tendency to coarse grain structure, especially in the case of castings that are slowly cooled, as would be typical for sand molds.

Modification of these alloys therefore aims to break up the $\alpha^{\prime}$ primary dendrites of the solid solution of zinc in aluminum which together with non-equilibrium eutectic comprise the basic microstructure.

The $\alpha^{\prime}$ solid solution crystallizes, similar to $\alpha(\mathrm{Al})$, in cubic lattice $\mathrm{A} 1$ of $\mathrm{Cu}-\mathrm{cP} 4$ type with space group $\mathrm{Fm} 3 \mathrm{~m}$ and lattice parameter $a=0.402-0.405 \mathrm{~nm}$, depending on the zinc content (Ref 16).

Therefore, for the modification of high-aluminum zinc alloys, titanium was used which is commonly used for modification of $\mathrm{Al}$ alloys, where refinement of the $\alpha(\mathrm{Al})$ grain structure is achieved after introduction of master alloys: Al-TiB (Ref 2, 25, 30), Al-Sr (Ref 17, 18), Al-RE (Ref 19-22), Al-Ti (Ref 23-26) and Al-Ti-C (Ref 34).
These additions result in a change in the morphology of the $\alpha^{6}$ dendrites from linear through petal-like to semi-globular. This change leads to a significant increase of ZA-27 alloy elongation, e.g., from about 5\% to about 15\% (Ref 2). Addition of Al-Sr master alloy to the ZA-27 alloy allows underside shrinkage to be avoided (Ref 17), while in ZA-10 alloy this addition causes structural refinement and enhances wear resistance (Ref 18). Addition of Al-RE to ZA-27 alloy slightly enhances its tensile strength and hardness and remarkably enhances its wear resistance (Ref 19); similar effects are achieved by the addition of RE together with Ti (Ref 20). RE addition to ZA-12 alloy is reported to enhance its toughness together with significant grain refinement (Ref 21). The grain refinement observed after addition of $0.2-0.8 \mathrm{wt} . \% \mathrm{Ce}$ to ZA10 alloy is non-uniform (Ref 22), and $\mathrm{Zn}_{2} \mathrm{Ce}$ or $\mathrm{Zn}_{3}$ Ce phases can act as nucleant particles. Addition of Al-Ti master alloy to chill-cast Zn-24 wt.\% Al (Ref 23, 24) and that of Al-Ti-B to $\mathrm{Zn}-25 \mathrm{wt} . \% \mathrm{Al}$ alloy solidifying in a graphite crucible (Ref 25) also cause significant refinement of the $\alpha(\mathrm{Al})$ grains. The refinement was attributed to the presence of $\mathrm{Al}_{5} \mathrm{Ti}_{2} \mathrm{Zn}$ nucleant particles (Ref 23,24) or particles of slightly different composition but satisfying the overall $\mathrm{Ti}(\mathrm{Al}, \mathrm{Zn})_{3}$ formula (Ref 25$)$. Studies performed in frame of Ref 26 showed that ZA-48 alloy doped with $0.02-0.1 \mathrm{wt} . \% \mathrm{Ti}$ (in Al-Ti master alloy) and cast into a steel mold shows increased elongation (from 5.8 to $7.6 \%$ ), the increase in UTS to about $430 \mathrm{MPa}$ and improved tribological properties. It was claimed that Ti-based nucleant particles had the composition $\mathrm{Al}_{66} \mathrm{Ti}_{25} \mathrm{Zn}_{9}$, but this strict composition, though satisfying $\mathrm{Ti}(\mathrm{Al}, \mathrm{Zn})_{3}$ formula, has not been confirmed in other publications.

Al-matrix master alloys require a melt temperature of 720$750{ }^{\circ} \mathrm{C}$ in order to ensure their rapid dissolution in the metal bath, while the technology of melting high-aluminum zinc alloys limits the temperature of the liquid alloy to about 600 $650^{\circ} \mathrm{C}$.

These disadvantages can be avoided by replacing Al-Ti master alloys with $\mathrm{Zn}$-Ti. The $\mathrm{Zn}$-Ti master alloys exhibit very good solubility in liquid $\mathrm{Zn}$-Al alloys at temperatures from above $450{ }^{\circ} \mathrm{C}$; furthermore, they have similar effect as $\mathrm{Al}-\mathrm{Ti}$ master alloys, i.e., they change the $\alpha^{6}$ dendrite morphology to semi-globular, while increasing elongation and preserving tensile strength (Ref 27, 28).

Another group of recently developed Al-Zn-based cast alloys are binary alloys with $\mathrm{Zn}$ content that increased to 10$50 \mathrm{wt} . \%$, or ternary Al-25Zn-(1-5)Cu designed for tribological applications (Ref 29) or designed for shape castings (Ref 3032 ). The nominal compositions of the examined alloys are among others: Al-35Zn (Ref 30), Al-(20-45)Zn-3Cu-0.4Fe$0.5 \mathrm{Si}(\operatorname{Ref} 31)$ and $\mathrm{Al}-(20-45) \mathrm{Zn}-2.5 \mathrm{Cu}-0.3 \mathrm{Fe}-0.4 \mathrm{Si}(\operatorname{Ref} 32)$. The mentioned alloys were gravity-cast into permanent molds (Ref 29-31) or were pressure die-cast (Ref 32). The Al-25Zn$3 \mathrm{Cu}$ alloy has the highest tensile strength and hardness, the best wear resistance and dimensional changes during aging as low as $0.02 \%$ (Ref 29$)$. The inoculation of binary Al-35Zn alloy by addition of Al-5Ti-1B master alloy reduced the grain size from $148 \mu \mathrm{m}$ in the initial alloy to about $27 \mu \mathrm{m}$ in the same alloy doped with $0.1 \% \mathrm{TiB}(\operatorname{Ref} 30)$. In the same work, it was noted that the optimal TiB addition was $0.05 \mathrm{wt} . \%$, giving the highest increase in UTS (from 322 to $383 \mathrm{MPa}$ ) and in elongation (from 7.3 to $13.8 \%$ ). For the $\mathrm{Al}-(20-45) \mathrm{Zn}-3 \mathrm{Cu}$ alloys reported in (Ref 31), increasing the $\mathrm{Zn}$ content from 20 to $45 \mathrm{wt} . \%$ decreases the grain size from about $320 \mu \mathrm{m}$ to about $100 \mu \mathrm{m}$. At the same time, the ultimate tensile strength (UTS) increases 


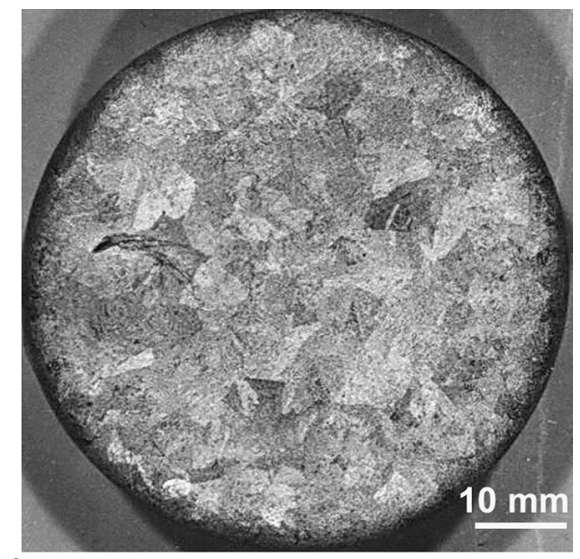

(a)

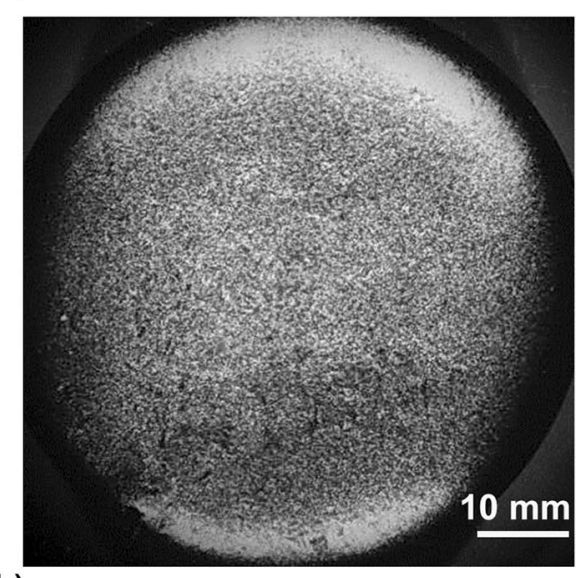

(b)

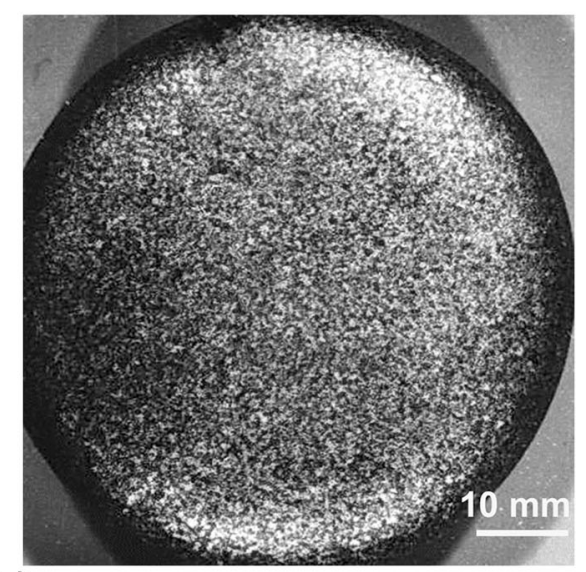

(c)

Fig. 2 Surfaces of cast samples of $\mathrm{Zn}-25 \mathrm{Al}$ alloy: (a) initial alloy, mean grain size $\sim 2750 \mu \mathrm{m}$; (b) the same alloy inoculated with $\mathrm{Zn}$ 4Ti master alloy, to $0.04 \mathrm{wt} . \% \mathrm{Ti}$, mean grain size $\sim 235 \mu \mathrm{m}$; (c) alloy (b) remelted 6 times, mean grain size $\sim 340 \mu \mathrm{m}$

from 315 to $455 \mathrm{MPa}$ and the elongation decreases from 4.5 to $3.1 \%$. The damping capacity (measured by logarithmic decrement) decreases by about $22 \%$ relative to the $\mathrm{Al}-20 \mathrm{Zn}-3 \mathrm{Cu}$ alloy, and Charpy absorbed-energy tests (performed on unnotched test bars) show the same tendency. The same authors examined die-cast alloys of slightly changed composition, with $\mathrm{Cu}$ content that reduced from 3 to $2.5 \mathrm{wt} \%$ (Ref 32). They noted that increasing $\mathrm{Zn}$ content increases the fluidity, Vickers hardness and UTS, decreases the elongation from about $7 \%$ to about $3 \%$ and decreases the coefficient of friction from about 0.4 (for Al-20Zn-based alloy) to about 0.2 (for Al-45Zn-based alloy).

In the literature cited above, the alloys were cast into permanent (metal or graphite) molds, but there is lack of studies based on sand-casting, the technology that is suitable for both high-aluminum zinc alloys (h-Al $\mathrm{Zn}$ ) and high-zinc aluminum alloys (h-Zn Al).

This work summarizes development of sand-cast highaluminum zinc alloys, represented by $\mathrm{Zn}-(25-26) \mathrm{wt} . \% \mathrm{Al}$, and high-zinc aluminum alloys represented by Al-(27-30) wt.\% Zn. The investigations focused on increasing ductility through structural refinement by inoculation and by partial substitution of $\mathrm{Cu}$ with $\mathrm{Ti}$ and/or $\mathrm{Mn}$ - aiming to improve structural stability while maintaining other properties. The results were obtained during joint investigations performed over the last few years at AGH University of Science and Technology in Krakow (Faculty of Foundry Engineering) and at University of Cambridge, UK (Department of Materials Science \& Metallurgy).

This work was presented at the 73rd World Foundry Congress in Krakow, September 2018, and addresses both academic and industrial interests in theory and practice related to Al-Zn-based cast alloys.

\section{Experimental Procedures}

The materials, melting and casting procedures, sample preparation and measurements techniques were the same as described previously (Ref 33-35).

The alloys Zn-26 wt.\% Al-2.2 wt.\% Cu (Zn-26Al-2.2Cu), Zn-26 wt.\% Al-1 wt.\% Cu-1.5 wt.\% Ti (Zn-26Al-1Cu-1.5Ti), Al-27 wt.\% Zn-2.5 wt.\% Cu (Al-27Zn-2.5Cu), Al-27 wt.\% Zn-2.5 wt.\% Cu-Ti (Al-27Zn-2.5Cu-Ti), Al-30 wt.\% Zn2 wt.\% Cu-1 wt.\% Mn (Al-30Zn-2Cu-1Mn) and master alloys Zn-4 wt.\% Ti (Zn-4Ti), Al-12.5 wt.\% Ti (Al-12Ti) and Al33 wt.\% $\mathrm{Cu}(\mathrm{Al}-33 \mathrm{Cu})$ were melted from electrolytic aluminum (minimum purity $99.96 \%$ ), electrolytic zinc $(99.995 \%)$, electrolytic copper (minimum purity $99.95 \%$ ) and titanium sponge (98-99.8\%, from Johnson Matthey Alfa). The Zn-Al, $\mathrm{Zn}-\mathrm{Al}-\mathrm{Cu}$ and $\mathrm{Al}-\mathrm{Zn}-\mathrm{Cu}$ alloys were melted in an electricresistance furnace, in an alumina crucible of 2-liter capacity. The Zn-4Ti and Al-12Ti master alloys were melted in a Balzers induction furnace with a protective argon atmosphere; the ingots of these alloys were the source of titanium. The melts of $\mathrm{Zn}-\mathrm{Al}$ and $\mathrm{Zn}-\mathrm{Al}-\mathrm{Cu}$ alloys were superheated to about $600{ }^{\circ} \mathrm{C}$, and Al-12Ti master alloy was added to give an overall titanium content of 1.5-1.6 wt.\% Ti. For grain refinement, Zn-4Ti master alloy was added to the $\mathrm{Zn}-\mathrm{Al}$ and $\mathrm{Zn}-\mathrm{Al}-\mathrm{Cu}$ alloys to the level of 50-400 ppm Ti. Commercial Al-3Ti-0.15C refiner (TiCAl) was added to the $\mathrm{Al}-27 \mathrm{Zn}-2.5 \mathrm{Cu}$ and $\mathrm{Al}-30 \mathrm{Zn}-2.5 \mathrm{Cu}-0.5 \mathrm{Mn}$ alloys to give an overall titanium content of $100 \mathrm{ppm}$. The Al(27-30)Zn-(1.5-2.5) Cu alloys were superheated to $720-740{ }^{\circ} \mathrm{C}$. Manganese was added to melt with Al-12 wt.\% Mn master alloy (Al-12Mn, from Alumetal, Poland). The melted charges were flushed with pure argon for $10 \mathrm{~min}$. Then, $10 \mathrm{~min}$ after finishing the flushing, the dross was removed from the melt surface. Five minutes after the Al-12Ti or Al-12Mn addition, the bath was stirred for $2 \mathrm{~min}$ with an alumina rod, and the alloys were cast into a dried green-sand mold with vertical cylindrical cavity $\varnothing 32 \times 80 \mathrm{~mm}(\operatorname{Ref} 34)$. 

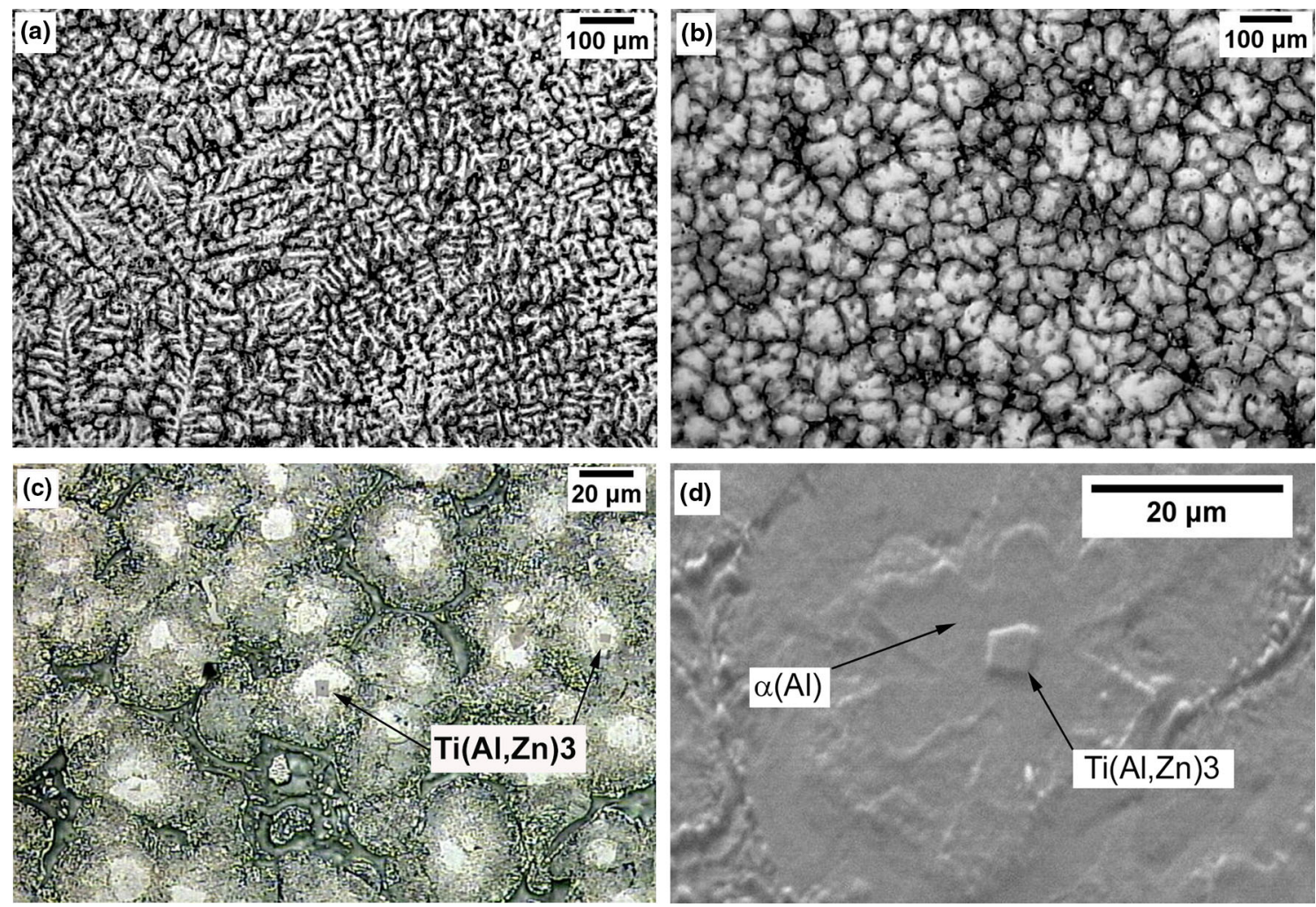

Fig. 3 Microstructures of sand-cast Zn-25Al alloy: (a) initial alloy with branched linear dendrites of $\alpha(\mathrm{Al})$; (b) the same alloy inoculated with $\mathrm{Zn}-4 \mathrm{Ti}$ master alloy, to $0.04 \mathrm{wt} \%$ Ti, with visible compacted, semi-globular $\alpha(\mathrm{Al})$ dendrites of sizes $\sim 50-180 \mu \mathrm{m}$; (c) and (d) examples of $\mathrm{Ti}(\mathrm{Al}, \mathrm{Zn})_{3}$ intermetallic particles inside refined $\alpha(\mathrm{Al})$ phase, mean particle size $\sim 4.28 \mu \mathrm{m}$

From these castings, samples $\varnothing 5 \times 35 \mathrm{~mm}$ were cut for dimensional measurements, $\varnothing 8 \times 24 \mathrm{~mm}$ for wear-resistance tests and $\varnothing 12 \times 25 \mathrm{~mm}$ samples for LM and SEM examination. The samples for dilatometry after supersaturation were homogenized in air in a furnace at $370-380{ }^{\circ} \mathrm{C}$ for $48 \mathrm{~h}$ and then quenched into water at room temperature. The dilatometry measurements were taken at room temperature using a screw micrometer of accuracy of $0.001 \mathrm{~mm}$. Results of, at least, 3 repeatable measurements were registered. Wear-resistance pinon-disk investigations were performed (T01 M device, Poland). Dry sliding-wear tests were against a rotating steel disk of 50 HRC, at a load giving 0.8 MPa pressure, and at a sliding speed of about $0.7 \mathrm{~m} / \mathrm{s}$, for a total sliding distance of $10 \mathrm{~km}$. The wear mass loss $W_{\mathrm{m}}(\mathrm{g} / \mathrm{Nm})$ and volume loss $W_{\mathrm{v}}\left(\mathrm{mm}^{3} / \mathrm{Nm}\right)$ were related to the load and sliding distance. The samples for light microscopy (LM) examination (Zeiss Axio Imager A2 m microscope) were ground on abrasive papers (grit 200-1000) and then were polished using sub-microscopic aluminum oxide in a water-alcohol suspension. The LM samples of Al-(2730)Zn-based alloys were etched using Barker's etchant. The LM samples of $\mathrm{Zn}$-(25-26) Al-based alloys were unetched. SEM/EBSD measurements were taken on unetched samples using JEOL JSM $5800 \mathrm{WV}$ with energy-dispersive spectrometry (Noran Voyager 3 EDS) and Quanta 3D FEG microscopes. The chemical composition of the analyzed phases was obtained using a SUTW-Sapphire detector and the EDAX ZAF procedure. 2D EBSD maps were acquired in low vacuum conditions at a water vapor pressure of 0.45 Torr using the EDAX Hikari camera. The operating parameters of the electron beam were: an accelerating voltage of $20 \mathrm{kV}$ and a beam current of $8 \mathrm{nA}$.
Diffraction patterns were analyzed at a rate of 50-100 patterns per second.

\section{Results}

Figure 2(a-c) shows the macrostructures of the $\mathrm{Zn}-25 \mathrm{Al}$ alloy. Figure 2(a) shows the macrostructure of the initial alloy, while Fig. 2(b) contrasts the same alloy modified with 0.04 wt.\% Ti after its first casting. The initial alloy without Ti addition shows a coarse macrostructure (Fig. 2a), while after 0.04 wt.\% Ti addition (with Zn-4Ti master alloy) it shows significant macrostructural refinement (Fig. 2b), which remains stable after several remeltings of the inoculated alloy (Fig. 2c).

Figure 3(a) and (b) shows the microstructure of the initial Zn$25 \mathrm{Al}$ alloy in its initial state, and after modification with $0.04 \mathrm{wt} . \%$ $\mathrm{Ti}$ after its first casting into a sand mold. The initial alloy without $\mathrm{Ti}$ addition shows a coarse dendritic structure of the $\alpha^{6} \mathrm{Zn}-\mathrm{Al}$ solid solution (Fig. 3a). After 0.04 wt.\% Ti addition, the solid solution shows a globular shape (Fig. 3b). Figure 3(c) and (d) shows examples of the $\mathrm{Ti}(\mathrm{Al}, \mathrm{Zn})_{3}$ particles revealed in the centers of the refined $\alpha^{6} \mathrm{Zn}-\mathrm{Al}$ solid solution. The role of these particles as nucleants of the $\alpha^{6} \mathrm{Zn}-\mathrm{Al}$ solid solution was discussed in detail in $(\operatorname{Ref} 27,28,33)$ and was also confirmed in $(\operatorname{Ref} 14,25)$.

Figure 4(a) shows the coarse dendritic structure of the initial Zn-26Al-2.2 Cu alloy, while Fig. 4(b) shows the refined structure of the same alloy in which $\mathrm{Cu}$ is partially replaced by Ti. From Fig. 4(c), it can be seen that the alloy with reduced $\mathrm{Cu}$ content shows much smaller dimensional changes during 

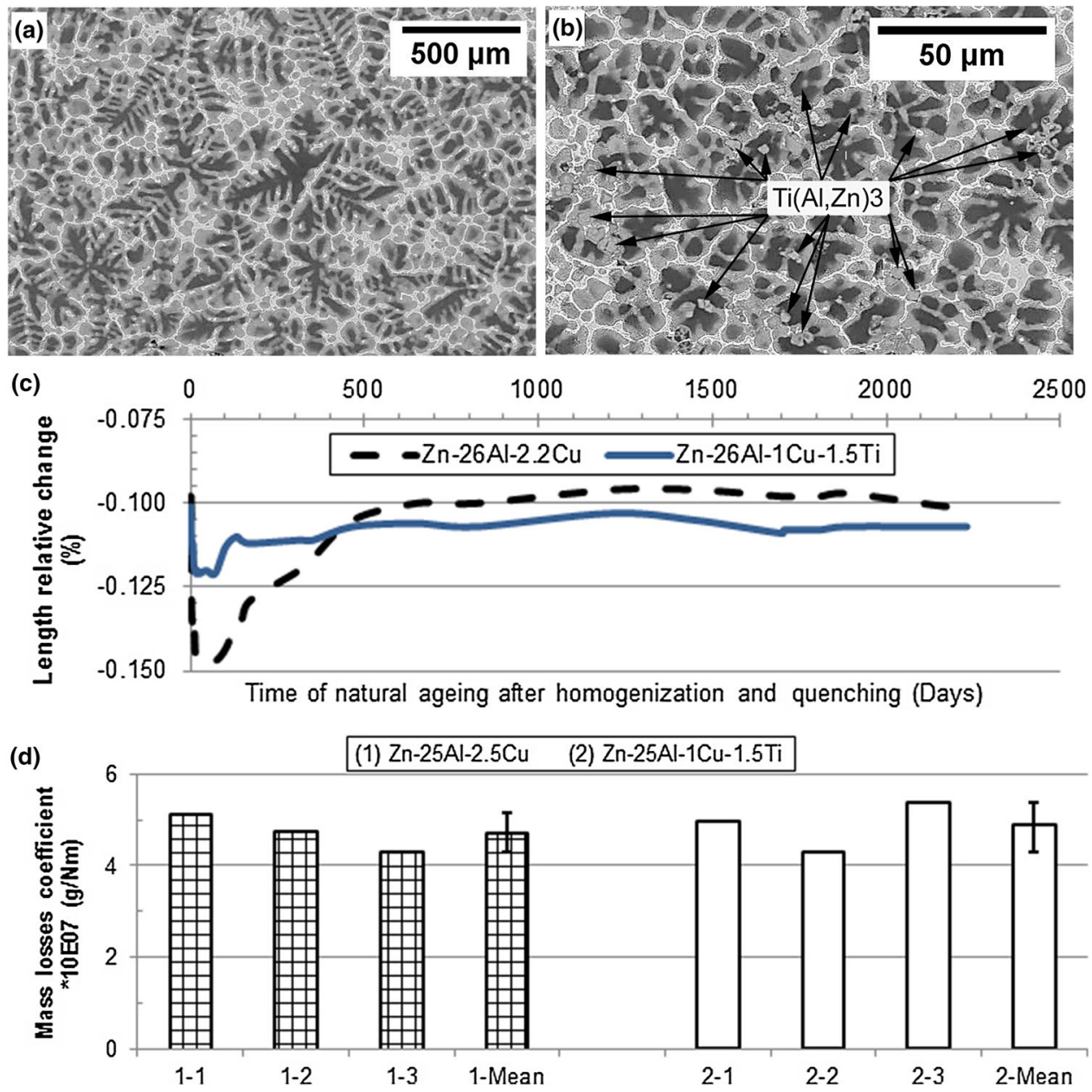

Fig. 4 Microstructure (a) and (b), dimensional changes (c) and wear resistance (d) of the high aluminum $\mathrm{Zn}-(25-26)$ wt.\% Al alloys. (a) Zn26Al-2.2Cu and (b) Zn-26Al-1Cu-1.5Ti. Mean size of Ti(Al,Zn) $)_{3}$ particles $\sim 4.3 \mu \mathrm{m}$

natural aging after homogenization and quenching. For practical purposes, this structure is stable in a very short time after quenching. The alloy $\mathrm{Zn}-26 \mathrm{Al}-1 \mathrm{Cu}-1.5 \mathrm{Ti}$ shows wear resistance of the same order as the initial Zn-26Al-2.2 Cu (Fig. 4d). The above results show that partial replacement of $\mathrm{Cu}$ with Ti gives a more stable structure while maintaining good wear properties.

Figure 5 shows similar results for high-zinc aluminum alloys, i.e., a coarse dendritic structure of the initial Al-27Zn$2.5 \mathrm{Cu}$ alloy (Fig. 5a) and a highly refined structure of the same alloy doped with $100 \mathrm{ppm}$ Ti introduced with Al-3Ti-0.15C refiner (Fig. 5b). Figure 5(c) and (d) shows exemplary microstructures of the coarse initial and grain-refined Al30Zn-based alloys containing Mn addition. From Fig. 5(e) and 5(f), it can be seen that the alloys with $\mathrm{Cu}$ content that reduced to $2-3$ wt.\% show a structure that is effectively stable during 1.5 -year natural aging after homogenization and quenching. It should be noted that the alloy Al-30Zn-2Cu-1Mn has better wear resistance than the Al-30Zn-3Cu alloy (Fig. 5f).

\section{Discussion}

The so-called high-zinc aluminum and high-aluminum cast alloys are now those alloys, which could replace other, more energy-consuming ones. Al-Zn alloys are economical to use because of their low melting point, low heating energy cost during production and their low weight that saves energy in transport applications. However, wider implementation of both these alloy types requires improving their mechanical properties and dimensional stability. The observed susceptibility to developing coarse grain structure in Al-Zn-based sand castings makes feeding difficult and decreases ductility. The highaluminum zinc alloys, e.g., ZA-27, are prone to overheating which increases gas pick-up and melt oxidation degrading the properties of the castings. The Zn-Ti-based master alloy used in these studies allows detrimental overheating to be avoided, because it is very soluble at temperatures as low as $500{ }^{\circ} \mathrm{C}$. From Fig. 3(a-c) and 4(a-d), it is seen that Zn-4Ti introduces particles that are very effective substrates for heterogeneous nucleation of the $\alpha(\mathrm{Al})$ matrix. The grain size of sand-cast $\mathrm{Zn}$ $25 \mathrm{Al}$ alloy doped with $0.04 \mathrm{wt} . \%$ Ti decreases ten times, from about $2.75 \mathrm{~mm}$ (Fig. 2a), to about $235 \mu \mathrm{m}$ (Fig. 2b). It is worth noting that this refinement is permanent, because after 6 remeltings the macrostructure remains still refined (Fig. 3c). It was noted in Ref 28 and Ref 33 that the $\mathrm{Zn}_{3}$ Ti phase introduced with the $\mathrm{Zn}$-Ti master alloy is a very effective and stable nucleant of the $\alpha(\mathrm{Al})$ matrix of the high-aluminum zinc alloys. This is true also for the $\mathrm{Ti}(\mathrm{Al}, \mathrm{Zn})_{3}$ particles introduced into the inoculated melt by partial substitution of $\mathrm{Zn}$ with $\mathrm{Al}$ in the binary $\mathrm{Zn}_{3}$ Ti phase (Ref 28). The refinement shown in Fig. 2 is 

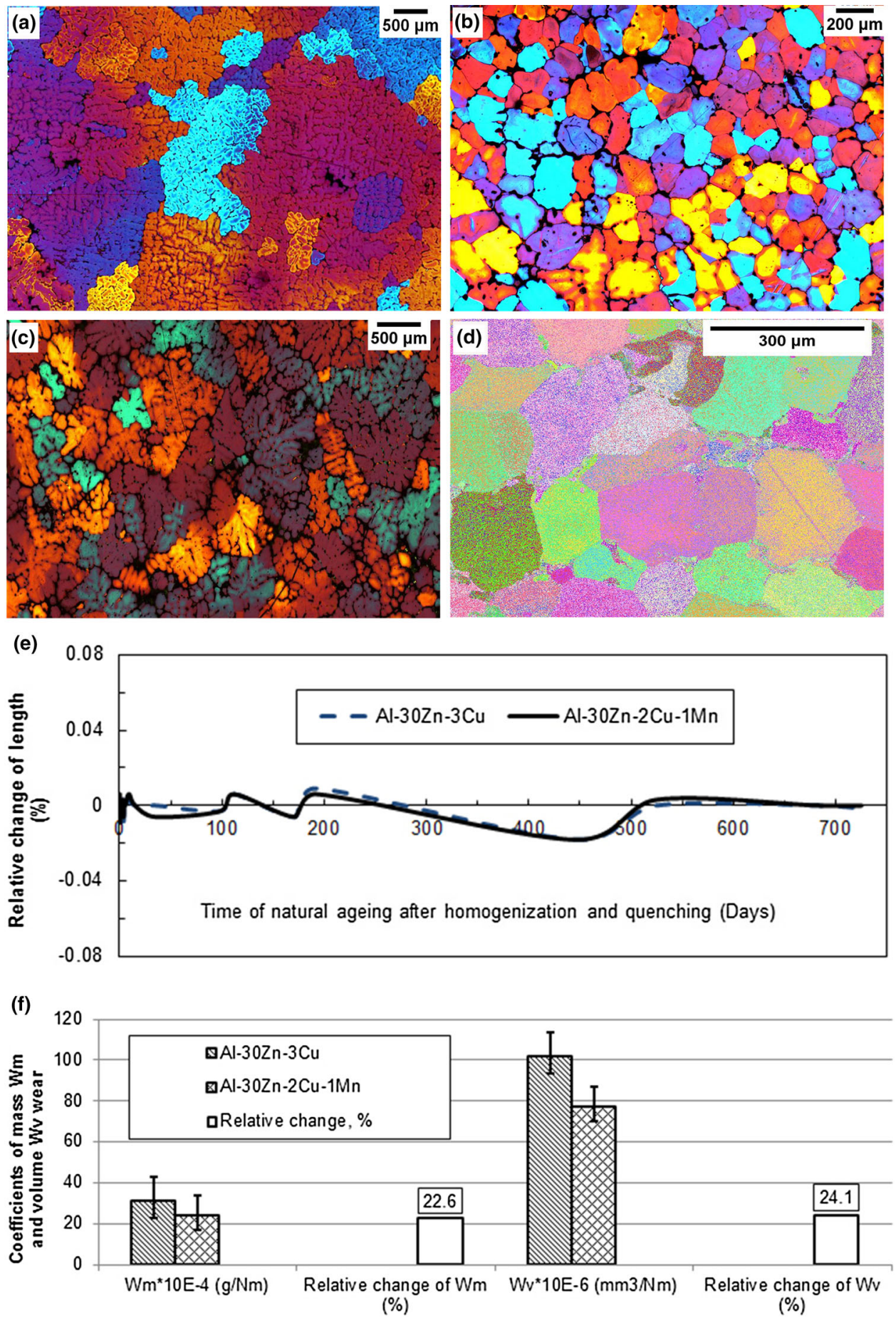

Fig. 5 Microstructure (a)-(d), dimensional changes (e) and wear resistance (f) of the high-zinc Al-(27-30) wt.\% Zn alloys. (a) Al-27Zn-2.5Cu. Mean grain size $\sim 1275 \mu \mathrm{m}$. (b) Al-27Zn-2.5Cu-Ti. Mean grain size $\sim 147 \mu \mathrm{m}$. (c) Al-30Zn-2.5Cu-0.5Mn. Mean grain size $\sim 880 \mu \mathrm{m}$. (d) Al30Zn-2Cu-1Mn-Ti. Mean grain size $\sim 146 \mu \mathrm{m}$

also confirmed in Fig. 3 that shows significant refinement of the $\alpha(\mathrm{Al})$ dendrites and change of their morphology from linear to semi-globular (Fig. 3a). The $\alpha(\mathrm{Al})$ matrix of the examined high-aluminum zinc alloys is nucleated with its $\{111\}$ plane parallel to $\{111\}$ of $\mathrm{L}_{2} \mathrm{Zn}_{3} \mathrm{Ti}$ or to $\{111\}$ of $\mathrm{L}_{2} \mathrm{Ti}(\mathrm{Al}, \mathrm{Zn})_{3}$ substrates (Ref 28). Taking this discussion into account, it can be concluded that the $\mathrm{Zn}$-Ti-based master alloys are promising inoculants for low-melting-point high-aluminum zinc foundry alloys. It should be also noted that the Zn-Ti-based master alloy enables melted alloys to be inoculated at temperature of about $600{ }^{\circ} \mathrm{C}$, i.e., $140{ }^{\circ} \mathrm{C}$ lower than $740{ }^{\circ} \mathrm{C}$ that is required when Al-Ti master alloy is used (Ref 23, 24).

The high-aluminum zinc alloys and high-zinc aluminum alloys with $\mathrm{Cu}$ addition (usually 3-5 wt.\%) have very good tribological properties due to the $\mathrm{Cu}$-rich bearing phase present in the soft matrix. The instability of structure and dimensions is caused by phase transformations of $\mathrm{CuZn}_{4}$ phase which take place in solid alloys over long periods after casting. That is why 
the $\mathrm{Cu}$ content should be reduced to $1.5-2$ wt.\%, i.e., to the amount that remains in solid solution. Unfortunately, reducing the $\mathrm{Cu}$ content degrades the tribological properties. This problem can be solved by partial substitution of $\mathrm{Cu}$ with another element, e.g., Ti and/or Mn, which also leads to the formation of bearing phases. For example, partial substitution of $1.2 \mathrm{wt} . \% \mathrm{Cu}$ with $1.5 \mathrm{wt} \% \% \mathrm{Ti}$ gives $\mathrm{Ti}(\mathrm{Al}, \mathrm{Zn})_{3}$ phase, particles of which are clearly visible in Fig. 4(b). The content of 1.2 wt. $\% \mathrm{Cu}$ remains in solid solution, while the ternary Tiparticles play the role of the bearing phase. The alloy with reduced $\mathrm{Cu}$ content shows improved dimensional stability (Fig. 4c) and also comparable wear resistance to the initial alloy without Ti addition (Fig. 4d). This is certainly an important advantage - improvement of structural stability while maintaining good wear resistance. Thus, partial replacement of $\mathrm{Cu}$ with $\mathrm{Ti}$ appears to be promising to decrease or eliminate structural instability while preserving good tribological properties of the high-aluminum zinc alloys.

Considering the high-zinc aluminum alloys, they similarly show rather low ductility after casting into sand molds; this is attributed to the coarse structure of the $\alpha(\mathrm{Al})$ matrix (Fig. 5a) which should be refined, e.g., through melt inoculation. It is commonly known that Al-3Ti-0.15C (TiCAl) master alloy introduces particles of $\mathrm{TiC}$ phase, which is a direct substrate for $\alpha(\mathrm{Al})$ nucleation. This role is confirmed in Fig. 5(b) which shows that inoculation of the sand-cast Al-(27-30) Zn- $(2-2.5) \mathrm{Cu}$ alloys with the TiCAl master alloy resulted in significant refinement of the $\alpha(\mathrm{Al})$ matrix phase, from about $1300 \mu \mathrm{m}$ (Fig. 5a) to about $150 \mu \mathrm{m}$ (Fig. 5b). Here the $\alpha(\mathrm{Al})$ matrix of the high-zinc aluminum alloys is nucleated with its $\{111\}$ plane parallel to $\{111\}$ of the TiC substrate (Ref 35). This inoculation increases elongation from about 2 to about $2.4 \%$ with basically preserved UTS on the level of 300-320 MPa (Ref 35). The high-zinc aluminum alloys usually contain $\mathrm{Cu}$, which gives the bearing phase and improves their tribological properties. However, the $\mathrm{Cu}$ content should be also reduced in this group of Al-Zn-based alloys to avoid possible dimensional instability. From Fig. 5(f), it is seen that partial substitution of $\mathrm{Cu}$ with $\mathrm{Mn}$ improves their wear resistance by about $22-24 \%$ (measured by mass and volume losses). At the same time, the length of the samples measured for over 2 years of natural aging after homogenization and quenching remained practically unchanged (Fig. 5e). Addition of 0.5 wt.\% Mn slightly decreases the size of the $\alpha(\mathrm{Al})$ grains, from about $1300 \mu \mathrm{m}$ (Fig. 5a) to about $900 \mu \mathrm{m}$ (Fig. 5c). Elucidation of this effect requires additional detailed examinations which will be performed and published in the near future.

\section{Conclusions}

The development of sand-cast high-aluminum zinc alloys and high-zinc aluminum alloys is aimed mainly at grain refinement and structural stabilization. The studies presented in the paper show that:

1. Using a Zn-Ti-based master alloy allows significant structural refinement of the high-aluminum zinc alloys without the detrimental melt overheating that would be required when Al-based refiners are used. The macrostructural refinement remains basically stable after several remelt- ings of the inoculated alloy. The observed grain refinement should improve the ductility of these alloys.

2. The ternary high-zinc aluminum alloys can be effectively refined with commercial Al-3Ti-0.15C (TiCAl) master alloy.

3. Partial replacement of $\mathrm{Cu}$ with $\mathrm{Ti}$ and/or $\mathrm{Mn}$ increases the dimensional stability of the examined alloys with preserving or increasing their good wear resistance. This advantage is of practical importance.

4. Future examinations should focus on the corrosion resistance, tensile strength, creep resistance and fatigue performance of the alloys examined in this work.

\section{Acknowledgments}

The authors are grateful to the NCN Polish Science National Centre for financial support under Grant No. UMO-2017/25/B/ ST8/00150. The AGH University of Science and Technology, Krakow, Poland-Faculty of Foundry Engineering, and The University of Cambridge, UK-Department of Materials Science and Metallurgy, are warmly acknowledged for provision of laboratory facilities.

\section{Open Access}

This article is distributed under the terms of the Creative Commons Attribution 4.0 International License (http://creativecommons.org/ licenses/by/4.0/), which permits unrestricted use, distribution, and reproduction in any medium, provided you give appropriate credit to the original author(s) and the source, provide a link to the Creative Commons license, and indicate if changes were made.

\section{References}

1. Censuses of World Casting Production, Modern Casting, Issues No. 12 from years 2008-2017

2. A.F. Skenazi, J. Pelerin, D. Coutsouradis, B. Magnus, and M. Meeus, Some Recent Developments in the Improvement of the Mechanical Properties of Zinc Foundry Alloys, Metall, 1983, 37, p 898-902

3. N. Karni, G.B. Barkay, and M. Bamberger, The Influence of Particle Size on the Properties of Die Cast ZA27 Based Metal-MatrixComposites, Giessereiforschung, 1994, 46, p 103-109

4. G. Ranganath, S.C. Sharma, M. Krishna, and M.S. Muruli, A Study of Mechanical Properties and Fractography of ZA-27/Titanium-Dioxide Metal Matrix Composites, J. Mater. Eng. Perform., 2002, 11, p 408413

5. H.J. Lo, S. Dionne, and M. Sahoo, Mechanical and Tribological Properties of Zinc-Aluminum Metal-Matrix Composites, J. Mater. Sci., 1992, 27, p 5681-5691

6. S.C. Sharma, B.M. Girish, B.M. Satish, and R. Kamath, Mechanical Properties of As-Cast and Heat-Treated ZA-27 Alloy/Short Glass Fiber Composites, J. Mater. Eng. Perform., 1998, 7, p 93-99

7. Y.H. Zhu, General Rule of Phase Decomposition in Zn-Al Based Alloys (II) - On Effects of External Stresses on Phase Transformation, Mater. Trans. JIM, 2004, 45, p 3085-3097

8. L. Jian, E.E. Laufer, and J. Masounave, Wear in Zn-Al-Si Alloys, Wear, 1993, 165, p 51-56

9. H. Wang, M. Luo, Y. Chen, and Y. Wu, The Time-TemperatureTransition (TTT) of ZA27 Alloy, J. Mater. Sci. Lett., 1996, 15, p 10061008

10. B.K. Prasad, Microstructure, Mechanical Properties and Sliding Wear Characteristics of Zn-Based Alloys: Effects of Partially Substituting Cu by Si, Z. Metallk., 1997, 88, p 929-935 
11. B.K. Prasad, A.K. Patwardhan, and A.H. Yegneswaran, Dry Sliding Wear Response of a Modified Zinc-Based Alloy, Mater. Trans. JIM, 1997, 38, p 197-204

12. R. Michalik, A. Iwaniak, and J. Wieczorek, Influence of Heat Treatment on the Wear Resistance of the ZnAl40Cu1.5Ti1.5 Alloy, Arch. Metall. Mater, 2017, 62(1), p 129-136

13. R. Michalik and B. Chmiela, Study on Nanohardness of Phases Occurring in ZnA122Cu3 and ZnAl40Cu3 Alloys, Arch. Metall. Mater. $2015,60(2)$, p 621-626

14. R. Michalik, Influence of Solution Heat Treatment on Phase Composition and Structure of ZnAl40Cu(1-2)Ti(1-2) Alloys, Arch. Metall. Mater., 2018, 63(1), p 461-466

15. R. Michalik and B. Chmiela, Influence of Solution Heat Treatment on Structure and Mechanical Properties of $\mathrm{ZnAl} 22 \mathrm{Cu} 3$ Alloy, Arch. Metall. Mater, 2016, 61(3), p 1581-1586

16. J.L. Murray, The Al-Zn (Aluminium-Zinc) System, J. Phase Equilib., 1983,4 , p 55-73

17. M. Sahoo, L.V. Whiting, V. Chartrand, and G. Weatherall, Effect of Strontium on the Structure and Mechanical Properties of $\mathrm{Zn}-\mathrm{Al}$ Foundry Alloys, J. AFS Trans., 1986, 94, p 225-242

18. M. Krupinski, M. Krol, B. Krupinska, K. Mazur, and K. Labisz, Influence of $\mathrm{Sr}$ Addition on Microstructure of the Hypereutectic Zn-Al-Cu alloy, J. Therm. Anal. Calorim., 2018, 133 p 255-260

19. D. Yang, J. Xie, A. Wang, and W. Wang, Effects of Rare Earth La on Microstructures, Mechanical Properties and Sliding Wear Behavior of High-Aluminium Zinc Foundry Alloy ZA30, Appl. Mech. Mater. 2011, 117-119, p 360-363

20. X. Zhao, H. Hu, P. Wang, G. Yang, and Q. Han, Microstructure and Properties of ZA-27TiRE Alloy, Rare Met., 1993, 12, p 16-20

21. Y. Chen, Effect of RE Elements on the Structure and Impact Toughness of Sand-Cast Zn-12\% Al Alloy, J. Alloys Compd., 1994, 206, p 169 173

22. M. Krupinski, Effect of Addition Ce on Crystallisation Kinetics and Structure of Zn-Al-Cu Alloys, Arch. Metall. Mater., 2018, 63(3), p 1173-1178

23. W.A. Pollard, K.M. Pickwick, J.T. Jubb, and R.H. Packwood, The Grain Refinement of Zinc-Aluminium Alloys by Titanium, Can. Metall. Q., 1974, 13, p 535-543
24. W.A. Pollard, Nucleation in Zn-Al Alloys Grain Refined with Ti, Can. Metall. Q., 1974, 13, p 597-606

25. A.A. Abdel-Hamid, Mechanism of Modifying Zn-Al Alloys by Ti, Ta, $\mathrm{Ti}+\mathrm{Ta}, \mathrm{V}, \mathrm{V}+\mathrm{Ti}, \mathrm{Zr}$ or Zr $+\mathrm{Ti}$, Z. Metallk., 1993, 84, p 40-43

26. S.Q. Yan and H.X. Wang, The Effect of Small Amount of Titanium Addition on the Grain Refinement and Mechanical Properties of ZA48 Alloy, J. Mater. Eng. Perform., 2013, 22, p 1113-1119

27. W. Krajewski, Investigation of the High-Aluminium Zinc Alloys Grain Refinement Process due to Ti Addition, Arch. Metall., 1999, 44, p 5164

28. W.K. Krajewski and A.L. Greer, EBSD Study of ZnA125 Alloy Inoculated with ZnTi4 Master Alloy, Mater. Sci. Forum, 2006, 508, p 281-286

29. T. Savaskan, O. Bican, and Y. Alemdag, Developing Aluminium-ZincBased a New Alloy for Tribological Applications, J. Mater. Sci., 2009, 44, p 1969-1976

30. S.S. Shin, G.Y. Yeom, T.Y. Kwak, and I.M. Park, Microstructure and Mechanical Properties of TiB-containing Al-Zn Binary Alloys, $J$. Mater. Sci. Technol., 2016, 32, p 653-659

31. S.S. Shin, K.M. Lim, and I.M. Park, Effects of High Zn Content on the Microstructure and Mechanical Properties of Al-Zn-Cu Gravity-Cast Alloys, Mater. Sci. Eng. A, 2017, 679, p 340-349

32. S.S. Shin, K.M. Lim, and I.M. Park, Characteristics and Microstructure of Newly Designed Al-Zn-based Alloys for the Die-Casting Process, $J$. Alloys Compd., 2016, 671, p 517-526

33. W.K. Krajewski, A.L. Greer, and P.K. Krajewski, Trends in Developments of High-Aluminium Zinc Alloys of Stable Structure and Properties, Arch. Metall. Mater., 2013, 58(3), p 845-847

34. W.K. Krajewski, J. Buras, P.K. Krajewski, A.L. Greer, K. Faerber, and P. Schumacher, New Developments of Al-Zn Cast Alloys, Mater. Today Proc., 2015, 2, p 4978-4983

35. W.K. Krajewski, A.L. Greer, J. Buras, G. Piwowarski, and P.K. Krajewski, New Developments of High-Zinc Al-Zn-Cu-Mn Cast Alloys, Mater. Today Proc., 2019, 10, p 306-311

Publisher's Note Springer Nature remains neutral with regard to jurisdictional claims in published maps and institutional affiliations. 